\title{
Diálogo da Gaivota
}

\section{Luiz Fernando Ramos \& Sílvia Fernandes}



uiz Fernando Ramos: O espetáculo Gaivota - tema para um conto curto encantou as platéias que o assistiram no teatro do Sesc Pinheiros de São Paulo, em 2007. Seria interessante pensar o que, exatamente, é tão fascinante naquele espetáculo, bem como sugerir porque, de algum modo, ele representa o ápice de um processo de radicalização, envolvendo o seu encenador, Enrique Diaz, a Cia dos Atores, comemorando 18 anos de trabalho, e os atores e atrizes agregados ao projeto. Esse conjunto de talentos encontrou na obra de Tchecov o aliado mais potente e, talvez, insuperável no radicalismo, na sua reconhecida trajetória de exploração de novos caminhos para a cena brasileira.

O mais surpreendente nessa encenação da Gaivota é como, mesmo abandonando completamente a preocupação de desenvolver o texto de forma literal, o espetáculo se revela tão ou mais fiel ao original do que o faria uma montagem convencional. A falta de uma narrativa sem fissuras, que buscasse a ilusão verossímil de ações emolduradas em uma situação dramática estável, não impede que um espectador que nunca tenha ouvido falar da peça possa acompanhar o seu desenvolvimento dramático essencial e mergulhar na alma de seus personagens. Ao contrá- rio, a opção pela instabilidade constante - tanto da cena, que se vai construindo como um esboço com permanentes ajustes dos traços, como dos personagens, que se vão substituindo entre os atores e muitas vezes se triplicando, atuando como coros - favorece uma compreensão muito mais profunda da peça. E esse é o primeiro mistério do espetáculo que valeria elucidar.

Uma das características dos processos de construção dramática no teatro contemporâneo é a ampliação dos limites do que antes se convencionava como o ato de atuar. Ainda vigente na maioria dos processos de criação ficcional que ocorrem no cinema e na televisão, o padrão do naturalismo histórico, em que o ator se esconde completamente no personagem, vem cada vez mais se reduzindo no âmbito do teatro, restando ainda, principalmente, nas encenações mais convencionais e que buscam o êxito comercial fácil. Muitos são os fatores que geraram essa transformação histórica nos últimos sessenta anos, mas a influência mais crucial talvez tenha sido a das idéias de Antonin Artaud, reverberadas nos anos 1960 no teatro de Jerzy Grotowski e, posteriormente, nas metodologias de Eugênio Barba e outros criadores das últimas décadas do século XX. Para sintetizar o sentido principal dessa transformação, vale

Luiz Fernando Ramos e Sílvia Fernandes são professores do Departamento de Artes Cênicas e do Programa de Pós-Graduação em Artes Cências da ECA-USP. 
dizer que a atitude do ator de se entregar plenamente à encarnação de um personagem, rendido à sua lógica e às circunstâncias ficcionais que o condicionam, é colocada em xeque. Nessa nova perspectiva, é inadmissível que não haja um diálogo entre a pessoa do ator e o personagem, uma negociação que, no mais das vezes, se sobressai aos próprios aspectos funcionais de suas participações no drama e acaba indo para a cena como matéria prima do encenador. Num certo sentido, poder-se-ia argumentar, o trabalho clássico de preparação do ator do naturalismo proposto por Stanislavski, de que o ator utilizasse suas experiências de vida como andaimes para a construção do personagem, avança o sinal das coxias e torna-se o tijolo mesmo da construção que chega aos olhos do público. $\mathrm{O}$ que fascina na montagem de Diaz de $A$ Gaivota é que esse jogo de fusão das matérias primas dos atores e dos personagens não se esgota na busca da obtenção de um melhor desempenho, mas torna-se também pretexto para uma abertura do texto, de sua estrutura dramática, ao exame do público. Isso quer dizer que o trabalho interno de montagem, e toda a especulação que atores e encenador engendraram no processo dos ensaios chegam na cena em igualdade de condições com o tecido ficcional traçado pelo dramaturgo. $\mathrm{O}$ resultado é um transbordamento do dramático e da ficção que, ao invés de enfraquecer o envolvimento do público, intensifica a fruição do espetáculo e atualiza os significados latentes da peça em termos muito mais vibrantes do que o fariam a simples compreensão da trama, ou o empático envolvimento emocional com os personagens.

Esses procedimentos são comuns a muitas companhias que vêm atuando contemporaneamente no Brasil e no exterior. A própria Cia dos Atores vem de uma bem sucedida aplicação desse método sobre um outro clássico da dramaturgia, Hamlet de Shakespeare. Ensaio. Hamlet foi um espetáculo que marcou o amadurecimento de companhia e a tornou conhecida internacionalmente. Assim como em $A$ Gaivo$t a$, ali o texto oferecia um vasto material para que o próprio ato de encenar um espetáculo fosse abordado e problematizado, e o jogo dos atores, trançando-se com os personagens para abrir a estrutura dramática ao exame do público, permitisse, também, uma leitura original e estimulante da peça. Dessa vez, talvez porque a peça de Tchecov seja mais explicitamente evocativa dos processos de encenação contemporâneos, o rendimento dessa dissecação de um clássico resultou ainda mais interessante. A opção por centrar a encenação em torno de um aspecto da peça nem sempre enfatizado - o fracasso da encenação do jovem Treplev diante de sua mãe, a grande atriz, Arkadina, que reverbera em todas as ações posteriores - permitiu que o tema central do espetáculo fosse a sua própria realização e a ameaça iminente dele próprio sucumbir. Esse trazer a ação à tona da cena, como que a deixando em carne viva diante do espectador, experimentou nesse caso um feliz e produtivo encontro: a tensa convivência entre a estrutura dramática genial criada pelo dramaturgo russo, que faz do abismo da criação artística o tema central da obra, e as próprias inquietações da companhia, lançada na aventura da criação e assumindo os riscos abismais de uma forma aberta e mutante.

Outro aspecto fascinante na montagem de Diaz é a discussão que estabelece com a idéia de representação. A começar do próprio ícone central da peça, a gaivota - representada de inúmeras e inusitadas maneiras, mas nunca de forma figurativa - um tema que perpassa todo o espetáculo é o da possibilidade de, no teatro, alcançar-se o máximo de significados com o mínimo de recursos. Assim, do lago que se forma a partir do café derramado, às asas que se armam a partir do foco de luz, há uma economia rigorosa a favorecer a condição de esboço, traço fugidio, que toda a encenação transpira. Como requinte máximo, nesse sentido, cite-se a tela inteiramente branca que, no mais das vezes, só é tingida sutilmente por figuras geométricas nas cores básicas. É uma evocação explícita das telas de Maliêvitch, o grande artista russo que primeiro, e de forma mais radical na histó- 
ria da pintura moderna, recusou a necessidade da pintura se apresentar a partir de um referente externo. A tela inteiramente branca, ou preta, terá como única referência a sua própria materialidade, ou cor. Da mesma forma, o espetáculo da Cia dos Atores, faz de si próprio, enquanto atualização contemporânea do teatro, o seu tema principal. A geringonça teatral desmontada, e exposta ao exame de seus procedimentos, oferece-se como matéria para a construção da poética cênica. Não é um poema fácil, ou pelo menos não busca a adesão irrestrita de um público acostumado às facilidades. Mas tem a simplicidade das grandes obras e se apresenta aos olhos com o carisma dos fatos inesquecíveis.

Sílvia Fernandes: Sem dúvida, o núcleo da cena é mesmo a capacidade que Enrique Diaz tem de abrir a estrutura do texto e os processos de ensaio permitindo que o trabalho interno da montagem chegue ao palco em igualdade de condições com a ficção tchekhoviana, como você diz bem. Nesse sentido, o abismo da criação artística é, de fato, o tema mais evidente do trabalho. Mas, quando o espetáculo terminou, tive a certeza de ter visto algo antológico, uma experiência de turning point no teatro brasileiro, como foram, para mim, Macunaima, de Antunes Filho, Trate-me Leão, do Asdrúbal Trouxe o Trombone, Eletra com Creta, de Gerald Thomas e $O$ livro de Jó, do Teatro da Vertigem. Talvez por isso, tenha ficado com a impressão de haver, na montagem, algo além da abertura de estruturas dramáticas e de representação, pois isso já estava no Ensaio. Hamlet e, com intensidade semelhante, em Melodrama e até em $A$ bao a $q u$. A primeira encenação que Enrique Diaz apresentou em São Paulo com a Companhia dos Atores, também escolhia, como tema e forma, os processos de criar. Não por acaso $A$ bao a qu se apresentava como um "canteiro de obras teatral”. Quase quinze anos depois da estréia, em 1991, a montagem ainda funciona como súmula de procedimentos que Enrique Diaz retoma e modifica em sua trajetória, e ainda surpreendem pela radicalidade.
Da mesma forma que espetáculos estreados na mesma época, como M.O.R.T.E., de Gerald Thomas, de 1990 e Exercício n. 1, de Bia Lessa, de 1987, A bao a qu também expunha o processo da criação artística num work-inprogress animado por um autor que encenava a metáfora da criação, usando a palavra concreta, a fisicalidade do ator, a materialidade do objeto e a disjunção espacial. Lembro, até hoje, do palco italiano do teatro João Caetano sendo paulatinamente preenchido por cadeiras, tijolos e vários tipos de pneus que, lançados aleatoriamente no espaço, desestabilizavam partituras de atuação e iluminação absolutamente rigorosas. Essa interferência do acaso (o espetáculo se inspirava no "Lance de dados", de Mallarmé) criava um movimento incessante de construção e desconstrução da cena, que às vezes envolvia os atores em fragmentos de tramas, supostamente dramáticas, intercaladas a partituras rítmicas que prescreviam tarefas de palco muito objetivas e relações pontuais com os objetos.

Se pensarmos nesse aspecto, de revelação dos mecanismos construtivos da cena e da atuação, $A$ Gaivota é a radicalização de um princípio anterior de criação. E que você detecta quando diferencia esse processo contemporâneo das propostas de Stanislavski, por exemplo. No caso do espetáculo de Enrique Diaz, o que mais interessa é mostrar como o ator chega ao personagem a partir de si mesmo, e não como lança mão de uma série de procedimentos para chegar à construção de uma personagem específica, que o precede enquanto concepção e conformação dramática.

E é exatamente dessa constatação que vem a pergunta. O que acontece na Gaivota que não acontecia nos outros trabalhos? É difícil dizer. Talvez o que o diferencie seja uma inquietação existencial latente, acentuada pelos processos que a dramaturgia de Tchekhov mobiliza (ou seria o inverso? Procura-se Tchekhov pela inquietação?). A verdade é que esse espetáculo abre um abismo na superfície carioca bemhumorada que prevalecia e que permitia, em geral, que o espectador se divertisse sem angústia. 
O problema é que, mesmo no humor, Tchekhov não costuma transigir, ainda mais em seu texto maior sobre os processos de criar. Treplev, o dramaturgo, suicida-se no final da peça. Nina, a aspirante a atriz, fracassa e quase enlouquece. Trigorin, o escritor consagrado, continua a passar pela vida em brancas nuvens, empalhando moças. Quanto à Arkádina, a grande dama dos realismos de Dumas Filho, continua a representação previsível de protagonistas tuberculosas. Mas é especialmente pela via da turbulência interior dos artistas/protagonistas da Gaivota que Tchekhov pergunta se é mais difícil criar ou viver.

Lendo o texto inteligente que Enrique Diaz publica no programa do espetáculo, é possível pensar na questão da temporalidade na cena, que o diretor enfatiza, depois de mencionar a "continuação de uma pesquisa de narrativa, de desconstrução, de uma relação particular com os clássicos, com os objetos e sobretudo com o tempo". A partir dessa referência, em grifo no original, dedicar o espetáculo aos filhos e aos pais faz todo sentido. Pois a instabilidade da vida e da criação teatral parece ser o núcleo volátil da peça. E o como fazer para articular a passagem do tempo de lá para o tempo de cá, o tempo do drama russo para o tempo da cena de hoje, é a pergunta que Diaz faz e o espetáculo responde. Articular os tempos é encontrar equivalentes dessa angústia da transitoriedade, da fugacidade da vida de uma sociedade e de um de teatro do final do século XIX que está neles e, de outra forma, em nós, que nascemos no XX e chegamos ao XXI como parceiros solidários dessa disjunção ao vivo ou, como você diz melhor, em carne viva: o fracasso do filho diante da mãe e do novo teatro frente ao tradicional, o desencontro amoroso, a vaidade, a cegueira, a superficialidade e a hipocrisia da atriz (e da representação?), a necessidade de criar um mundo especular diante da precariedade da vida, que acaba gerando uma instabilidade ainda maior. O lampejo temporal da situação passageira de um tipo de classe e de teatro é desdobrado na cena que não permanece, que é inconsistente até o inapreensível, a ponto de o espectador só perceber certas soluçôes quando elas já se dissolveram, como acontece com a relação nômade entre os atores e as várias personagens por onde passam, na projeção de uma cena migratória, indicada, por exemplo, nas fugazes asas de luz de Nina à beira do lago.

Há cerca de dois anos, assisti, no Rio de Janeiro, a um exercício que Enrique Diaz apresentou com seu grupo de intervenção urbana, o Coletivo Improviso, influenciado pela experiência com Anne Bogart, com quem estagiou no Saratoga International Theatre Institute. Diaz se aproxima dos viewpoints da encenadora americana quando estimula o ator a desenvolver a mestria dos movimentos e a definir seu desempenho também como domínio de formas plásticas no espaço, orientando-se por pontos de vista como o tempo, a repetição, a duração, o gesto, a forma, o padrão de trajetórias, as respostas cinestésicas e, evidentemente, o espaço.

E é fascinante constatar como os múltiplos pontos de vista aparecem radicalmente na Gaivota, especialmente nas soluções cênicas que se desmontam diante de nós para se remontarem mais à frente a partir de outro ângulo, como se o texto de Tchekhov fosse submetido a um caleidoscópio de pontos de vista e girasse sem parar, fisicamente, conforme quem assume o comando do olhar. E esse comando é dado pela subjetividade de uma visão singular, ou alguma coisa parecida com isso. Quando Mariana Lima, grávida de Enrique Diaz, fala do aborto de um filho imaginário, gerado pela personagem ficcional, cria o índice mais claro da performance dos atores.

Mas talvez o que mais impressione na Gaivota - tema para um conto curto seja a junção do trabalho de teatro, em sentido concreto, e da criação da cena imaginária, que aparece numa das indicaçôes do lago, quando as três atrizes varrem a terra do chão enquanto formam seu contorno. Elas limpam o palco - são trabalhadoras de teatro - e ao mesmo tempo constroem a cena - são atrizes de teatro. Jamais personagens. Esse tempo já passou. 